\title{
Differences in biological traits composition of benthic assemblages between unimpacted habitats
}

Bolam, S.G.; Garcia, C.; Eggleton, J.; Kenny, A. J.; Buhl-Mortensen, Lene; Gonzalez-Mirelis, G.; Kooten, Tobias van; Dinesen, Grete E.; Hansen, Jørgen L.S.; Hiddink, J.G.

Total number of authors:

18

Published in:

Marine Environmental Research

Link to article, DOI:

10.1016/j.marenvres.2017.01.004

Publication date:

2017

Document Version

Peer reviewed version

Link back to DTU Orbit

Citation $(A P A)$ :

Bolam, S. G., Garcia, C., Eggleton, J., Kenny, A. J., Buhl-Mortensen, L., Gonzalez-Mirelis, G., Kooten, T. V., Dinesen, G. E., Hansen, J. L. S., Hiddink, J. G., Sciberras, M., Smith, C., Papadopoulou, N., Gumus, A., Van Hoey, S., Eigaard, O. R., Bastardie, F., \& Rijnsdorp, A. D. (2017). Differences in biological traits composition of benthic assemblages between unimpacted habitats. Marine Environmental Research, 126, 1-13.

https://doi.org/10.1016/j.marenvres.2017.01.004

\section{General rights}

Copyright and moral rights for the publications made accessible in the public portal are retained by the authors and/or other copyright owners and it is a condition of accessing publications that users recognise and abide by the legal requirements associated with these rights.

- Users may download and print one copy of any publication from the public portal for the purpose of private study or research.

- You may not further distribute the material or use it for any profit-making activity or commercial gain

- You may freely distribute the URL identifying the publication in the public portal 


\section{Accepted Manuscript}

Differences in biological traits composition of benthic assemblages between unimpacted habitats

S.G. Bolam, C. Garcia, J. Eggleton, A.J. Kenny, L. Buhl-Mortensen, G. GonzalezMirelis, T. van Kooten, G. Dinesen, J. Hansen, J.G. Hiddink, M. Sciberras, C.

Smith, N. Papadopoulou, A. Gumus, G. Van Hoey, O.R. Eigaard, F. Bastardie, A.D.

Rijnsdorp

PII:

S0141-1136(16)30186-6

DOI:

10.1016/j.marenvres.2017.01.004

Reference: MERE 4265

To appear in: Marine Environmental Research

Received Date: 19 October 2016

Revised Date: 6 January 2017

Accepted Date: 22 January 2017

Please cite this article as: Bolam, S.G., Garcia, C., Eggleton, J., Kenny, A.J., Buhl-Mortensen, L., Gonzalez-Mirelis, G., van Kooten, T., Dinesen, G., Hansen, J., Hiddink, J.G., Sciberras, M., Smith, C., Papadopoulou, N., Gumus, A., Van Hoey, G., Eigaard, O.R., Bastardie, F., Rijnsdorp, A.D., Differences in biological traits composition of benthic assemblages between unimpacted habitats, Marine Environmental Research (2017), doi: 10.1016/j.marenvres.2017.01.004.

This is a PDF file of an unedited manuscript that has been accepted for publication. As a service to our customers we are providing this early version of the manuscript. The manuscript will undergo copyediting, typesetting, and review of the resulting proof before it is published in its final form. Please note that during the production process errors may be discovered which could affect the content, and all legal disclaimers that apply to the journal pertain. 
Differences in biological traits composition of benthic assemblages between unimpacted habitats

3

4 Bolam, S.G. ${ }^{1 *}$, Garcia, C. ${ }^{1}$, Eggleton, J. ${ }^{1}$, Kenny, A.J. ${ }^{1}$, Buhl-Mortensen, L. ${ }^{2}$, Gonzalez-Mirelis, G. ${ }^{2}$, 5 van Kooten, T. ${ }^{3}$, Dinesen, G. ${ }^{4}$, Hansen, J. ${ }^{4}$, Hiddink, J.G. ${ }^{5}$, Sciberras, M. ${ }^{5}$, Smith, C. ${ }^{6}$, Papadopoulou, 6 N. ${ }^{6}$, Gumus, A. ${ }^{7}$, Van Hoey, G. ${ }^{8}$, Eigaard, O.R. ${ }^{4}$, Bastardie, F. ${ }^{4}$, Rijnsdorp, A.D. ${ }^{3}$

$8 \quad{ }^{1}$ The Centre for the Environment, Fisheries and Aquaculture Sciences (Cefas), Lowestoft, NR33 9 OHT, UK

$10 \quad{ }^{2}$ Institute of Marine Research (IMR), Bergen, Norway

$11{ }^{3}$ Institute for Marine Resources and Ecosystem Studies (IMARES), P.O. Box 68, 1970 AB IJmuiden, 12 The Netherlands

$13{ }^{4}$ National Institute for Aquatic Resources, Technical University of Denmark, Charlottenlund Castle, Charlottenlund 2920, Denmark

${ }^{5}$ School of Ocean Sciences, Bangor University, Menai Bridge, Anglesey, LL59 5AB, UK

${ }^{6}$ Hellenic Centre for Marine Research, Attiki Greece (HCMR)

${ }^{7}$ Ondokuz Mayis University, Samsum, Turkey

${ }^{8}$ Institute of Agricultural and Fisheries research (ILVO), Ankerstraat 1; 8400 Oostende; Belgium 


\section{ABSTRACT}

There is an implicit requirement under contemporary policy drivers to understand the characteristics of benthic communities under anthropogenically-unimpacted scenarios. We used a trait-based approach on a large dataset from across the European shelf to determine how functional characteristics of unimpacted benthic assemblages vary between different sedimentary habitats.

Assemblages in deep, muddy environments unaffected by anthropogenic disturbance show increased proportions of downward conveyors and surface deposit-feeders, while burrowing, diffusive mixing, scavenging and predation traits assume greater numerical proportions in shallower habitats. Deep, coarser sediments are numerically more dominated by sessile, upward conveyors and suspension feeders. In contrast, unimpacted assemblages of coarse sediments in shallower regions are proportionally dominated by the diffusive mixers, burrowers, scavengers and predators. Finally, assemblages of gravelly sediments exhibit a relatively greater numerical dominance of non-bioturbators and asexual reproducers. These findings may be used to form the basis of ranking habitats along a functional sensitivity gradient.

Key words: biological traits; infauna; unimpacted assemblages; European shelf 


\section{INTRODUCTION}

Spatial variation of macrobenthic populations and their associated assemblages is an integral component of the ecology of the marine benthos, including conservation of its biodiversity. As a consequence, many studies have been conducted specifically to understand such variation and how it is driven by variations in the physical environment (e.g., depth, sediment type) (e.g. Cabioch, 1968; Barrio-Frojan et al., 2012). However, to understand how important functional properties of benthic assemblages are maintained, knowledge of both their structural and functional aspects is indispensable (Elliott and Quintino, 2007; Van Hoey et al., 2010). Moreover, while assessments based on changes in the abundance of indicator species and/or community structure are invaluable for monitoring change or for assessing seabed status, insights regarding important ecosystem processes can only be gained from information about the functional properties of benthic assemblages. Unfortunately, the functional characteristics of these assemblages are presently largely undescribed.

Studies conducted to acquire the necessary benthic data needed to understand the role of benthic assemblages in driving ecological processes explicitly need to encompass large spatial scales. The acquired data must also originate from anthropogenically-undisturbed regions to ensure the observed faunal and ecological relationships represent natural senarios. While such surveys can be designed to exclude areas likely to be impacted by localised anthropogenic activities (e.g., dredged material disposal, marine aggregate extraction), it is difficult for largescale spatial surveys to exclude the impacts associated with more ubiquitous pressures such as bottom trawling. Spatial scale differences between benthic grabs and the grid cells used to process VMS (vessel monitoring system) data (approx. $\mathrm{km}^{2}$ ) makes VMS data of limited value to overcome this issue. Fishing with mobile bottom-contacting gears (bottom trawling and dredging; referred to as 'fishing' hereafter) undoubtedly represents one of the most widespread anthropogenic pressures imposed on the seabed (Collie et al., 2000; Kaiser et al., 2002; Eastwood et al., 2007; Halpern et al., 2008). In UK waters, the footprint of fishing is estimated to account for over $99 \%$ of the known footprint of all human pressures on the seabed (Foden et al., 2011). Meanwhile, Eigaard et al. (2016a) documented that across European waters, the footprint of bottom trawling ranges between $22-99 \%$ and $4-68 \%$ for depth bands $0-200 \mathrm{~m}$ and $201-1000 \mathrm{~m}$, respectively.

Over the past fifty years, many studies have been conducted to specifically progress our understanding of the impacts of fishing on seabed communities. Although observed impacts tend 
to vary by gear type, fishing intensity and the nature of the seabed (Kaiser and de Groot, 2000; Tillin et al., 2006), the studies consistently reveal that the activity results in a shift in species composition towards smaller, fast-growing, short-lived taxa (Jennings and Kaiser, 1998; Kaiser et al., 2000, 2002; Hiddink et al., 2007; van Denderen et al., 2015). Such profound effects of fishing on both the structural and functional composition of seabed assemblages across habitats imply that unless variations in fishing intensity are accounted for, the capacity for large-scale studies to improve our understanding of the natural spatial variability and ecological functioning of assemblages will inherently be compromised. This issue is currently of particular relevance with respect to compliance with contemporary legislative drivers. For instance, there is an implicit obligation under the Marine Strategy Framework Directive (CEC, 2008) and the ecosystem approach to management (Rice, 2003) to understand the characteristics of benthic communities under unimpacted scenarios to allow realistic ranges of indicators describing baseline situations to be determined.

While directly measuring ecological function (e.g., secondary production, oxygen flux) remains time-consuming and can be methodologically and logistically difficult (Crisp, 1984; Tagliapietra et al., 2007), the recent development of a number of numerical approaches has allowed scientists to better estimate seabed functioning (Thrush et al., 2014; Bolam et al., 2016). The application of Biological Traits Analysis (BTA) to marine benthic data, for example, has provided an enhanced understanding of the changes in benthic functioning along environmental gradients (Dimitriadis et al., 2012; Van Son et al., 2013). Utilising assemblage information to determine what the organisms do within the ecosystem (i.e. their 'traits') as opposed to merely determining their taxonomic identity (i.e. what they are) potentially offers great advances into our understanding of the functioning of benthic assemblages (Snelgrove, 1997; Bremner, 2008; Webb et al., 2009).

We used a trait-based approach on a large dataset from across the European shelf to identify correlative relationships between functional characteristics of benthic assemblages and environmental parameters. Variations in the numerical proportions of various functional traits (Voille et al., 2007) are used as a proxy for functional variability. Data from samples collected at 812 stations across a range of sedimentary habitats were used to:

(1) Describe the functional structure of infaunal assemblages and patterns of spatial distribution; and

(2) Identify the main environmental factors that were mainly responsible for these spatial patterns. 
A numerical approach was initially applied to the data to delineate stations displaying significant signs of fishing-induced changes in traits composition from those representing an unfished composition. The stations used were also away from areas influenced by other anthropogenic pressures. Thereby, this study describes the baseline trait composition of benthic assemblages not subject to contemporary anthropogenic pressure. This work was undertaken as part of an EU-funded project Benthis (http://www.benthis.eu/en/benthis.htm) which aims to study the impacts of fishing on benthic ecosystems and provide the science base to assess the impact of current fishing practices. The data compiled for the current study will also be used within the project to quantify the impacts of fishing on benthic traits and how this affects food availability for commercially-important fish (Depestle et al., in prep). The assessment of how traits vary between different habitats when not subjected to man-induced pressure, therefore, forms an integral part of a wider assessment on fishing impacts.

\section{METHODS}

\subsection{Biological data}

Benthic macrofaunal data from a large geographical area across the European shelf were collated for this study to ensure that the analyses and subsequent results pertained to a range of marine sedimentary habitats, e.g., deep mud, shallow coarse sediments (Figure 1, Table 1). No stations were located within zones of impact associated with licensed activities such as dredged material disposal, aggregate extraction, renewable energy infrastructure. Comparability of data among the different regional datasets was aided through the following: (i) only data collected in spring and summer were used; and (ii) only samples sieved through a $1 \mathrm{~mm}$ sieve mesh were included in the analysis. Meanwhile, trait-area curves (analogous to species-area curves) revealed that trait diversity did not differ significantly among different benthic sampling devices (i.e. sampling area and device penetration depth) (Cefas, unpubl. data). Therefore, infaunal data collected using different sampling devices were included in the analysis. 

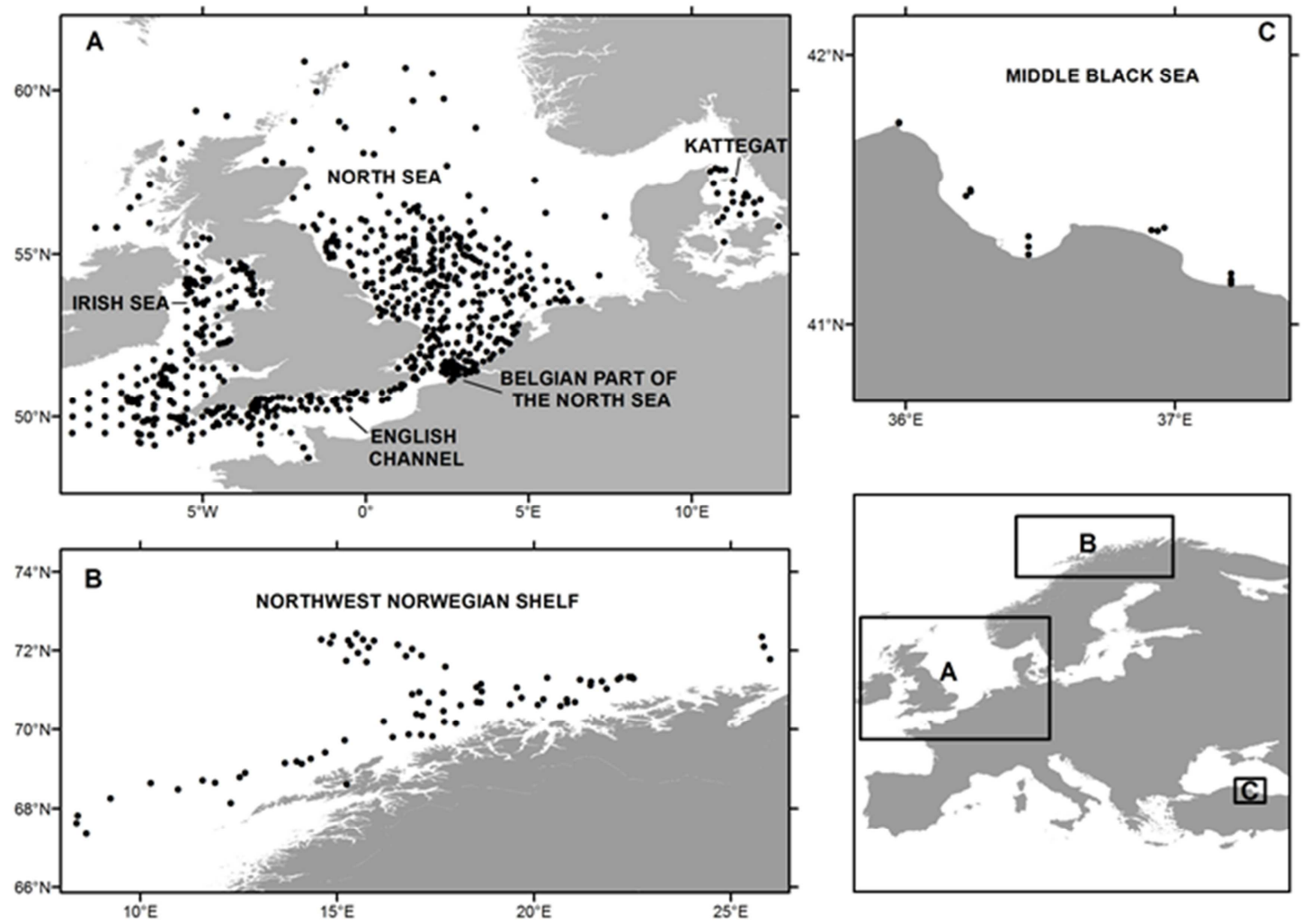

Figure 1. Distribution of the 812 stations for which biological trait composition data were acquired. Stations shown represent varying fishing intensities, thus, not all were subsequently classed as unfished and taken forward for traits composition analyses. 
Table 1. Summary of source data used for the traits analysis.

\begin{tabular}{|c|c|c|c|c|}
\hline Region & $\begin{array}{l}\text { No. } \\
\text { stations }\end{array}$ & Years & Sampling device & $\begin{array}{l}\text { Mesh } \\
\text { (mm) }\end{array}$ \\
\hline Irish Sea (Hiddink et al., 2009) & 23 & 2007 & $\begin{array}{l}\text { Day grab, Box corer (both } \\
0.1 \mathrm{~m}^{2} \text { ) }\end{array}$ & 1 \\
\hline $\begin{array}{l}\text { North Sea, English Channel } \\
\text { (Bolam et al., 2014) }\end{array}$ & 511 & $2000-09$ & $\begin{array}{l}\text { NIOZ corer, mini-Hamon and } \\
\text { Day grab (all } 0.1 \mathrm{~m}^{2} \text { ) }\end{array}$ & 1 \\
\hline Middle Black Sea & 18 & 2013 & $0.1 \mathrm{~m}^{2}$ van Veen grab & 1 \\
\hline Kattegat & 22 & 2006 & $0.01 \mathrm{~m}^{2}$ Haps corer & 1 \\
\hline Belgian part of North Sea & 59 & 2004-08 & $0.1 \mathrm{~m}^{2}$ van Veen grab & 1 \\
\hline Southern North Sea & 100 & $1995-2010$ & $0.08 \mathrm{~m}^{2} \mathrm{NIOZ}$ corer & 1 \\
\hline Northwest Norwegian shelf & 79 & $2006-11$ & $\begin{array}{l}0.25 \mathrm{~m}^{2} \text { van Veen grab, } 0.1 \mathrm{~m}^{2} \\
\text { Box corer }\end{array}$ & 1 \\
\hline Total stations & 812 & & & \\
\hline
\end{tabular}

2.2 Biological traits

A suite of eight biological traits were considered relevant to describe important functional attributes of the macrofaunal assemblages (Table 2). There is currently no accepted methodology for selecting the most appropriate traits for a given study (Marchini et al., 2008) and often the final selection is partly guided by the limited biological information available for benthic invertebrate taxa (Bremner, 2008; Marchini et al., 2008; Bolam and Eggleton, 2014). Since the use of traits in this study was to serve as a proxy for assemblage function, we focussed on functional traits, although, in reality, our understanding of which macrofaunal traits contribute to benthic functioning is presently limited. Functional traits are those that are expressed in phenotypes of organisms that are considered relevant to the response to the environment and/or their effects on ecosystem properties (Voille et al., 2007). Functional traits, which underpin both species' contributions to ecosystem properties and services and their tolerance to environmental stressors and disturbance, therefore, lie at the crossroads between functional effect and response traits (Diaz et al., 2013).

Each of the traits was subdivided into multiple modalities chosen to encompass the range of possible attributes of all the taxa (Table 2). Many taxa display multi-faceted behaviour depending upon, for example, the prevailing conditions or resources available (Usseglio-Polatera et al., 2000). Therefore, a "fuzzy-coding" approach was adopted (Chevenet et al., 1994), assigning a score between 0 and 3 to each modality, depending on the affinity of that taxon for that modality, where 0 conveys no affinity, 
1641 or 2 express partial affinity and 3 indicates total and exclusive affinity (Bolam and Eggleton, 2014).

165 These scores were then converted to proportions totalling to one for each trait. The resulting taxon-

166 by-trait matrix was combined with the taxon abundance-by-station (No. per $\mathrm{m}^{2}$ ) matrix to create the

167 final station-by-trait matrix on which all subsequent trait analyses were based. Macrofaunal

168 abundance was selected as the traits weighting factor as the alternative, biomass data, were only

169 available for a subset of the data.

170 
Table 2. Description of traits and trait modalities used in the biological traits analysis.

172

\begin{tabular}{|c|c|c|}
\hline Trait & Trait modalities & Trait modality description \\
\hline \multirow[t]{6}{*}{ Maximum size } & $<10($ sr10) & Maximum size (length or height) of adult (mm) \\
\hline & $10-20(s r 10-20)$ & \\
\hline & $21-100(s r 21-100)$ & \\
\hline & $101-200(\operatorname{sr} 101-200)$ & \\
\hline & $200-500(s r 200-500)$ & \\
\hline & $>500(\operatorname{sr} 500)$ & \\
\hline \multirow[t]{4}{*}{ Longevity } & $<1(I 1)$ & The maximum lifespan of the adult stage $(\mathrm{y})$ \\
\hline & $1-3(\mid 1-3)$ & \\
\hline & $3-10(\mid 3-10)$ & \\
\hline & $>10(\mid 10)$ & \\
\hline \multirow{3}{*}{$\begin{array}{l}\text { Larval } \\
\text { Development } \\
\text { Location }\end{array}$} & Pelagic Planktotrophic (IdPel) & Larvae feed and grow in the water column \\
\hline & Pelagic Lecithotrophic (IdLec) & Larvae feed on yolk reserves \\
\hline & Benthic (direct) (IdDir) & Larval stage missing (eggs develop into juvenile forms) or larvae are limited to the bed \\
\hline \multirow{4}{*}{$\begin{array}{l}\text { Egg Development } \\
\text { Location }\end{array}$} & Asexual / budding (edAsex) & $\begin{array}{l}\text { Species can reproduce asexually, either by fragmentation, budding, epitoky, etc. Often this is in } \\
\text { addition to some form of sexual reproduction }\end{array}$ \\
\hline & Sexual - pelagic eggs (edPel) & Eggs are released into the water column \\
\hline & $\begin{array}{l}\text { Sexual - benthic eggs } \\
\text { (edBen) }\end{array}$ & Eggs are released onto/into the bed, either free or maintained on bed by mucous or other means \\
\hline & $\begin{array}{l}\text { Sexual - brood eggs } \\
\text { (edBrood) }\end{array}$ & Eggs are maintained by adult for protection, either within parental tube or within body cavity \\
\hline \multirow[t]{5}{*}{$\begin{array}{l}\text { Sediment } \\
\text { Position }\end{array}$} & Surface (spSurf) & Found on or just above the seabed \\
\hline & Shallow infauna, & $\begin{array}{l}\text { Species whose bodies are found almost exclusively below sediment surface between } 0 \text { and } 5 \mathrm{~cm} \\
\text { sediment depth }\end{array}$ \\
\hline & $0-5 \mathrm{~cm}(\mathrm{sp} 0-5)$ & \\
\hline & $\begin{array}{l}\text { Mid-depth infauna, } 5-10 \mathrm{~cm} \\
\text { (sp5-10) }\end{array}$ & $\begin{array}{l}\text { Species whose bodies are partly or exclusively found below sediment surface at a depth generally } \\
\text { between } 5 \text { and } 10 \mathrm{~cm} \text { sediment depth }\end{array}$ \\
\hline & Deep-infauna, $>10 \mathrm{~cm}(\mathrm{sp} 10)$ & Species whose bodies are partly or exclusively found below sediment surface at a depth greater than \\
\hline
\end{tabular}


Trait

Trait modalities

\begin{tabular}{|c|c|}
\hline \multirow{5}{*}{ Feeding mode } & Suspension (fSusp) \\
\hline & Surface deposit (fSurf) \\
\hline & $\begin{array}{l}\text { Sub-surface deposit (fSub- } \\
\text { surf) }\end{array}$ \\
\hline & $\begin{array}{l}\begin{array}{l}\text { Scavenger / opportunist } \\
\text { (fScav) }\end{array} \\
\end{array}$ \\
\hline & Predator (fPred) \\
\hline Mobility & Sessile (mSess) \\
\hline
\end{tabular}

Swim (mSwim)

Crawl/creep/climb (mCrawl)

Burrowers (mBurrow)

Diffusive mixing (bDiff)

Surface

deposition

(bSurfDep)

Upward conveyor (bUpward)

Downward conveyor

(bDownward)

Bioturbation
None (bNone)

Trait modality description

$10 \mathrm{~cm}$ sediment depth

The removal of particulate food taken from the water column, generally via filter-feeding

Active removal of detrital material from the sediment surface. This class includes species which scrape and/or graze algal matter from surfaces

Removal of detrital material from within the sediment matrix

Species which feed upon dead animals

Species which actively predate upon animals (including the predation on smaller zooplankton) Species in which the adults have no, or very limited, mobility either because they are attached or are limited to a (semi-) permanent tube or burrow Species in which the adults actively swim in the water column (many usually return to the bed when not feeding)

Capable of some, generally limited, movement along the sediment surface or rocky substrata Infaunal species in which adults are capable of active movement within the sediment

Vertical and/or horizontal movement of sediment and/or particulates 


\subsection{Categorising stations to habitats}

All stations were assigned to a level 4 EUNIS habitat class (Davies et al., 2004) using sediment particle size data acquired from samples taken at each station and associated depth information (Table 3). Classifying each station to a EUNIS habitat based on its actual sediment type and depth as opposed to that predicted by EUSeaMap overcomes incorrect assignments by the latter which often results from its inability to accommodate small-scale sediment variability (Cameron and Askey, 2011). Although the EUNIS system has drawbacks (Galparsoro et al., 2012), it was chosen here as a method to categorise the stations into environmentally-similar groups due to its application within a number of European policies (e.g. the Habitats Directive, the Marine Strategy Framework Directive) as a means ensuring a common shared path and technical terminology between Member States.

Table 3. Number of stations and mean depth, mud and gravel content of the various EUNIS habitats. EUNIS habitat for each station was based on observed particle size distribution and depth.

\begin{tabular}{llcccc} 
EUNIS & EUNIS description & $\begin{array}{c}\text { No. stations in } \\
\text { total }\end{array}$ & Mean depth (m) & $\begin{array}{c}\text { Mean mud } \\
\text { content (\%) }\end{array}$ & $\begin{array}{c}\text { Mean gravel } \\
\text { content (\%) }\end{array}$ \\
\hline A5.13 & Infralittoral coarse sediment & 24 & 22 & 2 & 27 \\
A5.14 & Circalittoral coarse sediment & 86 & 47 & 2 & 33 \\
A5.15 & Deep circalittoral coarse & 49 & 87 & 2 & 19 \\
A5.23 & Infralittoral fine sand & 90 & 25 & 2 & 1 \\
A5.24* & Infralittoral muddy sand & 14 & 14 & 18 & 1 \\
A5.25 & Circalittoral fine sand & 168 & 35 & 2 & 0 \\
A5.26 & Circalittoral muddy sand & 59 & 36 & 21 & 0 \\
A5.27 & Deep circalittoral sand & 181 & 148 & 15 & 1 \\
A5.33* & Infralittoral sandy mud & 4 & 11 & 50 & 1 \\
A5.35* & Circalittoral sandy mud & 11 & 31 & 72 & 0 \\
A5.37 & Deep circalittoral mud & 67 & 559 & 75 & 0 \\
A5.43* & Infralittoral mixed sediments & 11 & 20 & 17 & 26 \\
A5.44 & Circalittoral mixed sediments & 24 & 39 & 19 & 27 \\
A5.45 & Deep circalittoral mixed & 24 & 338 & 30 & 19
\end{tabular}

* habitat removed from further analyses due to insufficient number of stations $(<20)$.

The first step in determining the sampling stations whose macrofaunal assemblages were unaffected by fishing was to estimate the fishing pressure (FP) for each station. FP estimates were derived using a state-of-the-art methodology regarding the calculation of fishing pressure metrics from official catch and effort statistics as described by Eigaard et al. (2016a; 2016b). In summary, VMS data (from 2010 to 2012 (incl.)) were combined with logbook data, together with estimates regarding the dimensions of the different gears. Statistical modelling of the vessel size or vessel engine power $\sim$ gear size relationships for different métiers (combinations of gear types and target 
species) were then conducted. The unit for the FP estimates is the ratio of the cell swept area over the total grid cell area used in the model $\left(\mathrm{km}^{2}\right.$ in area). An FP estimate of 1 signifies that the full extent of the grid cell is swept once per year on average (FP can be $>1$ ) while FP $=0.5 \mathrm{y}^{-1}$ infers that $50 \%$ of the $\mathrm{km}^{2}$ grid cell is fished within a year. The numbers of stations with FP estimates of zero, 0 $-0.5 y^{-1}$ and $>0.5 y^{-1}$ for each habitat are shown in Table 4.

Table 4. Number of stations estimated as exhibiting FP=0, $0<F P<0.5$, and $F P>0.5 \mathrm{y}^{-1}$.

\begin{tabular}{llllll}
$\begin{array}{l}\text { EUNIS } \\
\text { code }\end{array}$ & EUNIS habitat description & $\begin{array}{l}\text { No. } \\
\text { stations }\end{array}$ & FP $=0$ & $0<F P<0.5$ & FP $>0.5$ \\
\hline A5.13 & Infralittoral coarse sediment & 24 & 7 & 3 & 14 \\
A5.14 & Circalittoral coarse sediment & 86 & 2 & 33 & 51 \\
A5.15 & Deep circalittoral coarse sediment & 49 & 1 & 27 & 21 \\
A5.23 & Infralittoral fine sand & 90 & 2 & 15 & 73 \\
A5.25 & Circalittoral fine sand & 168 & 1 & 35 & 132 \\
A5.26 & Circalittoral muddy sand & 59 & 3 & 16 & 40 \\
A5.27 & Deep circalittoral sand & 181 & 2 & 68 & 111 \\
A5.37 & Deep circalittoral mud & 67 & 15 & 11 & 41 \\
A5.44 & Circalittoral mixed sediments & 24 & 0 & 11 & 13 \\
A5.45 & Deep circalittoral mixed sediments & 24 & 2 & 10 & 12
\end{tabular}

To define the FP cut-off value which delineates between the unfished and fished assemblages for each habitat, we assumed that (i) the stations with estimates of zero FP represent the natural or baseline trait compositions for the habitat, (ii) there is a point at which an increase of fishing pressure results in a detectable change in the traits composition compared to the unfished state, and (iii) a trait 'diversity' proxy that incorporates the entirety of the traits composition represents a suitable metric to quantify a holistic change in trait composition. Furthermore, the level of fishing pressure at which changes in traits composition occur is likely to be habitat-specific (Buhl-Mortensen et al., 2015).

Functional Diversity (FD; Petchey and Gaston, 2002) was used as the metric to quantify changes in trait composition within increases in FP. For the present study, the FD calculation was adapted from the initial community functional diversity calculation, i.e. based on a species/trait matrix (Petchey and Gaston, 2002), to a protocol based on a station/traits matrix. This is logical since a station-bytrait composition matrix adopts a comparable format as that of a species-by-trait matrix typically used to calculate community functional diversity. The advantage of using this method here is that as the index is not influenced by species richness, the number of stations per se will not strongly influence the FD values (Petchey and Gaston, 2002). 
The FD value of the 'reference' situation for each habitat was first calculated (Figure 2). This was done using the traits data from all stations with $\mathrm{FP}=0$; this was possible for seven EUNIS habitats while for three habitats (e.g. A5.15, A5.25, A5.44) there were fewer than two stations with FP $=0$ (Table 4). For these, the two stations with the lowest FP estimates were used for the reference point. The resulting FD value was considered as a first point of reference against which the FD value based on the addition of a third station (displaying the next highest FP estimate) was compared (Figure 2). This new value then became the second point of reference against which the FD value based on the inclusion of the fourth station was compared. The FD value following the addition of each station is compared to the FD value prior to its addition to determine the 'jump' in FD. The station-specific contribution to FD, not the overall FD, is being quantified. This procedure was continued until all the stations along the gradient of increasing FP for each habitat had been included. 


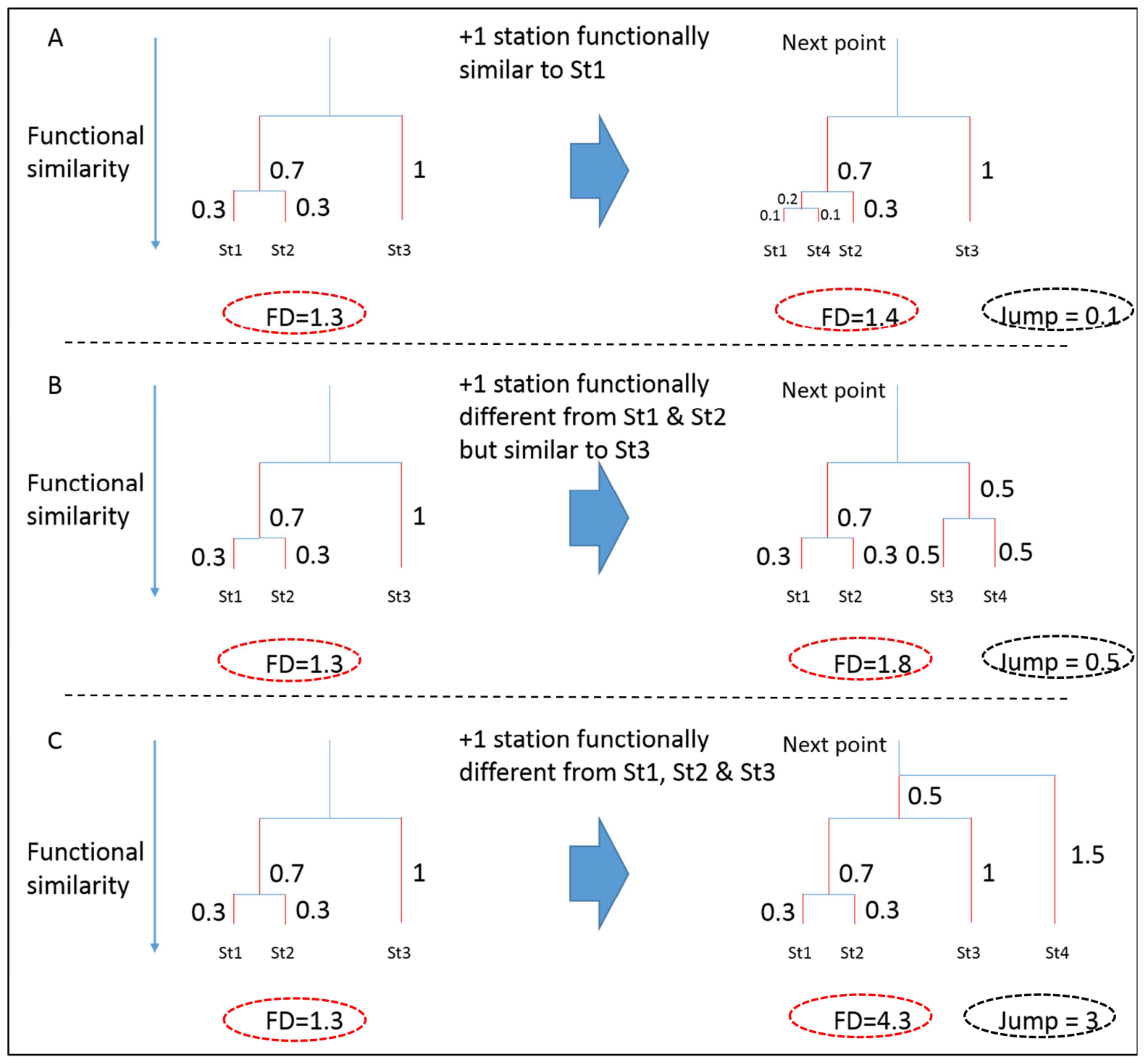

Figure 2. Example of the effect on functional diversity (FD) following the addition of a station (station 4). The magnitude of the change, or 'jump', is calculated by adding the red branch lengths. ' $A$ ' shows the jump (FD goes from 1.3 to 1.4 , jump $=0.1$ ) when the next station has a comparable traits composition to those of the existing set of stations, 'B' shows the jump (FD goes from 1.3 to 1.8 , jump $=0.5$ ) when the traits composition of the new station shows some trait composition difference, and ' $C$ ' shows the jump (FD goes from 1.3 to 4.3 , jump $=3$ ) when the traits composition of the next station is compositionally very different from those of the previous stations.

The magnitudes of change in FD (or jumps) following the addition of each successive station along a gradient of increasing fishing pressure were then plotted for each habitat (Figure 3). A small difference in FD inferred a small trait composition change, while a large difference in FD signified a large modification to trait composition associated with the addition of that station (as explained in Figure 2). The distribution frequencies of the FD jumps for each habitat denoted that it was acceptable to assume normality, therefore, the accepted upper threshold of outliers in a normal distribution was used to derive a significance threshold, based on quantile $3+1.5 \times$ IQR (Inter 
256 Quantile Range). The FD change threshold between those stations exhibiting trait compositions

257 comparable to those of the reference trait compositions, or "unfished" hereafter, and those displaying a trait composition significantly divergent from the reference, or "fished" hereafter, was determined by the first change in FD above the significance threshold for a fishing pressure greater than $0 \mathrm{y}^{-1}$ (Figure 3). Where the initial jump in FD for a habitat corresponded to a station with FP $=0$ (e.g. A5.15: deep circalittoral coarse sediment), the next significant jump value was used as the first cut-off. 
A5.14

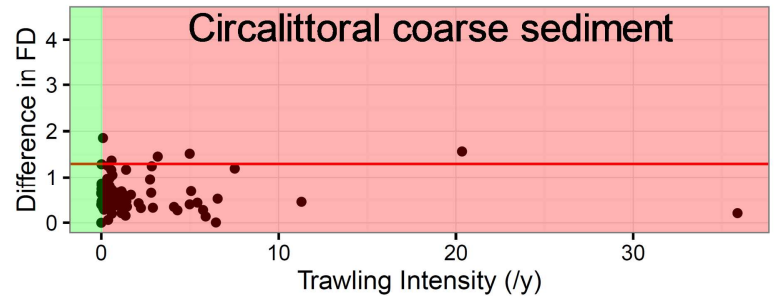

A5.15

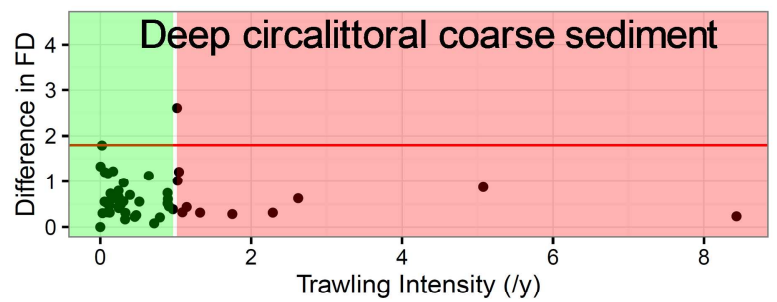

A5.25

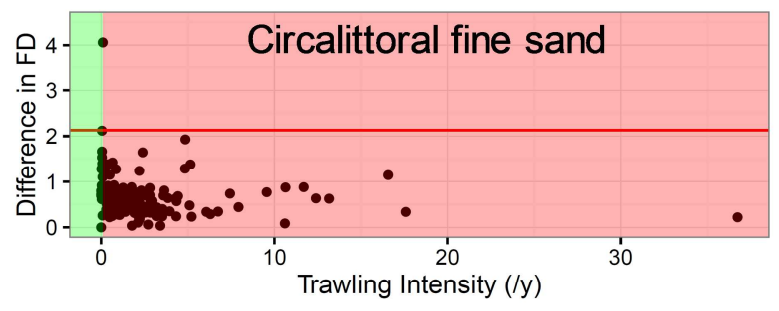

A5.26

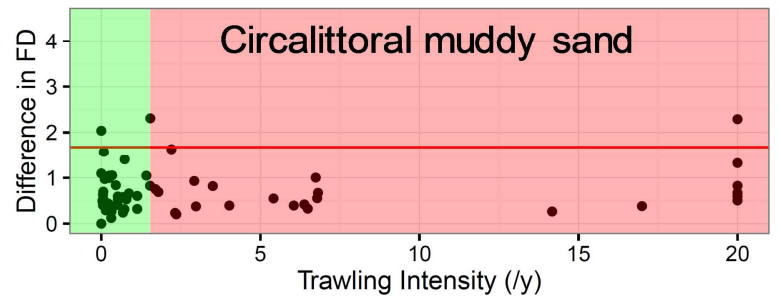

A5.27

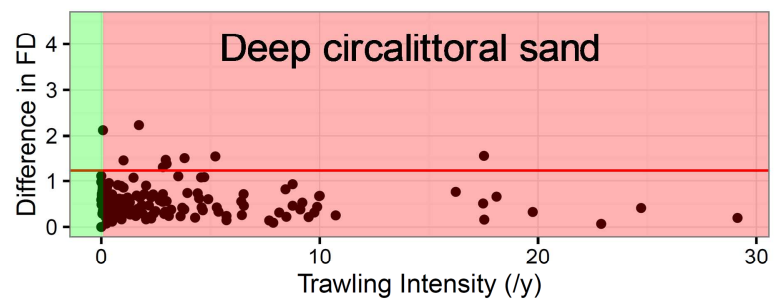

A5.37

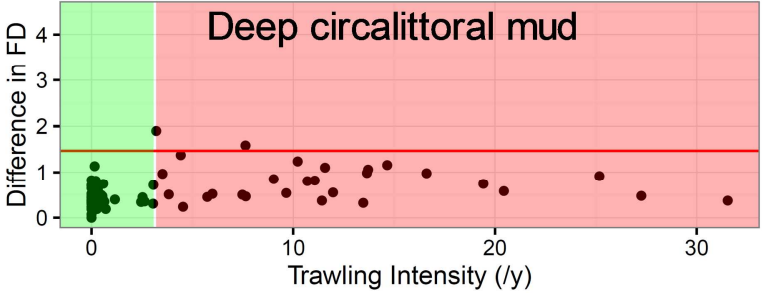

A5.44

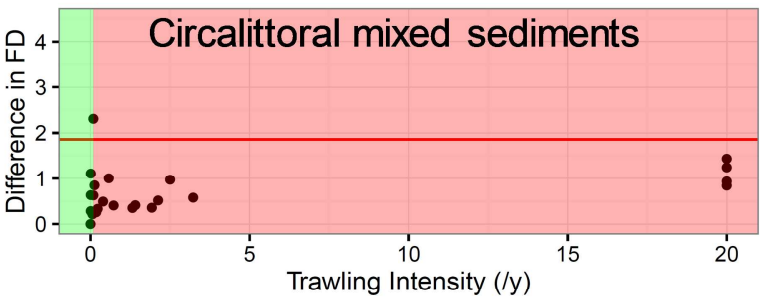

A5.13

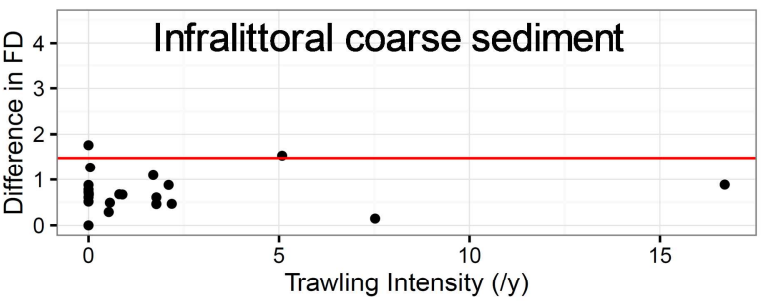

A5.23

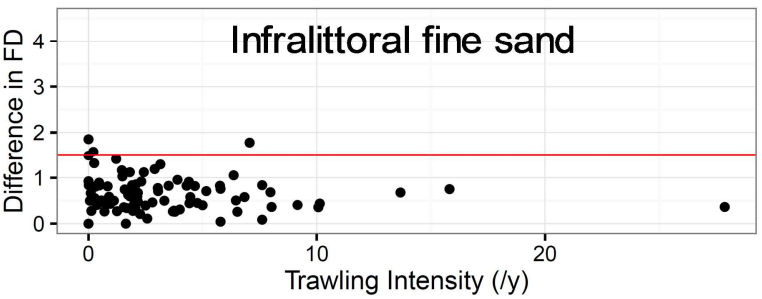

A5.45

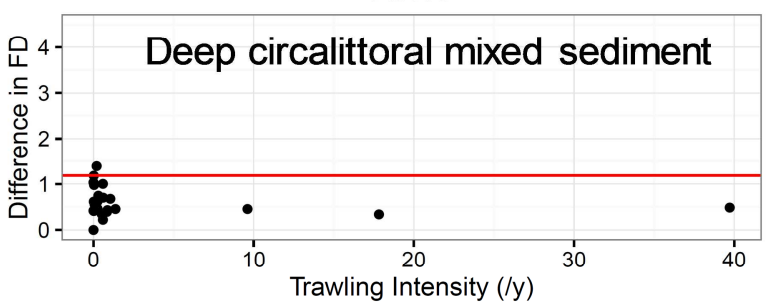

Figure 3. Magnitude of increases in FD associated with each station when added to the preceeding reference situation for the habitat. The red horizontal line shows the theoretical outlier limit in a normal distribution; the first point (with an FP>0) above the significant change threshold line is assumed to mark the transition between unfished (green) and stations whose trait assemblage are modified by increased fishing activity (red). A delineation between unfished and fished assemblages using this approach (see main text) could not be defined for A5.13, A5.23, A5.45.

For three EUNIS habitats; A5.13: infralittoral coarse sediment, A5.23: infralittoral fine sand, and A5.45: deep circalittoral mixed sediment, the cut-off point resulted in the acquisition of too few 
unfished stations to allow a meaningful assessment of traits composition for unfished assemblages for the habitat (Figure 3). These habitats were therefore removed from further analyses.

For seven EUNIS habitats, this method yielded a successful separation between assemblages whose traits composition of an unfished scenario could be discerned from one of a fished situation (Figure 3, Table 5). The FP cut-off between fished and unfished assemblages varied between these habitats; the cut-off for A5.14 (circalittoral coarse sediment), A5.25 (circalittoral fine sand), A5.27 (deep circalittoral sand) and A5.44 (circalittoral mixed sediment) was less than $0.1 \mathrm{y}^{-1}$, that for A5.15 (deep circalittoral coarse sediment) and A5.26 (circalittoral muddy sand) approximated 1 and $1.5 \mathrm{y}^{-1}$ respectively, while the cut-off FP for A5.37 (deep circalittoral mud) was over $3 \mathrm{y}^{-1}$ (Table 5). Importantly, the approach resulted in a large increase in the number of stations for which traits composition can be suitably used to describe the unfished situation of each habitat compared to that based on using stations with $\mathrm{FP}=0$ (Table 5).

Table 5. FP cut-off values based on traits composition for each Eunis habitat.

\begin{tabular}{|c|c|c|c|c|}
\hline $\begin{array}{l}\text { EUNIS } \\
\text { code }\end{array}$ & $\begin{array}{l}\text { EUNIS combined } \\
\text { description }\end{array}$ & $\begin{array}{l}\text { No. stations } \\
\qquad P P=0 y^{-1}\end{array}$ & $\begin{array}{c}\text { FP cut-off } \\
y^{-1}\end{array}$ & $\begin{array}{l}\text { Resulting No. } \\
\text { unfished stations }\end{array}$ \\
\hline A5.14 & Circalittoral coarse & 2 & 0.07 & 17 \\
\hline A5.15 & Deep circalittoral & 1 & 0.97 & 37 \\
\hline A5.25 & Circalittoral fine sand & 1 & 0.09 & 14 \\
\hline A5.26 & Circalittoral muddy & 3 & 1.53 & 33 \\
\hline A5.27 & Deep circalittoral sand & 2 & 0.08 & 20 \\
\hline A5.37 & Deep circalittoral mud & 15 & 3.1 & 38 \\
\hline A5.44 & Circalittoral mixed & 0 & 0.09 & 6 \\
\hline
\end{tabular}

The number of stations with $\mathrm{FP}=0 \mathrm{y}-1$ and those classed as unfished according to their trait composition (section 2.4) is also shown.

\subsection{Analyses of trait composition}

The assemblage traits data of all the stations classified as unfished following the procedure outlined in Section 2.4 were then selected and ordinated using multivariate analysis. Because of the fuzzy nature of trait composition data, Fuzzy-Correspondence Analysis (FCA), an extension of correspondence analysis for fuzzy-coded data, was performed (Thioulouse et al., 1997). Two reduced 2-dimensional standardised ordination plots were produced from this analysis. One FCA plot displays the relative similarities between the samples based on their traits composition. A 
second FCA plot displays the 35 trait modalities as vectors with respect to their relative importance in driving the relative similarity of samples in the first ordination plot. In order to extract the most important trait modalities driving the sample variance, the method developed by Linting et al. (2011) for Principal Component Analysis was adopted. The significance of each trait modality was then determined using a non-parametric approach of a permutation test. This test allowed a determination of whether the contributions of each modality to the total variance accounted for (VAF) could have been achieved by chance alone, or if they were significant at 95\% (Linting et al. 2011).

Finally, binomial GLMs were used to explore the respective contributions of each available environmental variable for each sample (namely gravel and mud content of the sediment and station depth) against the location of each sample on axes 1 and 2 in the FCA plot. The binomial distribution was choosen due to the percentage nature of sediment data and because the observed depth values along axis 2 inferred that a binomial GLM would also be appropriate for depth. We translated the raw depth data into percentages in order to perform the analysis; the maximum depth across all habitats what set at $100 \%$. All numerical analyses were conducted using the $\mathrm{R}$ package, Version R-3.3.1 (R Core Team, 2014).

\section{RESULTS}

\subsection{Traits composition variability of unimpacted assemblages}

The variability in traits composition of unfished assemblages for each of the seven EUNIS habitats for which unfished assemblages could be described are presented in the FCA plots in Figure 4. The first two axes accounted for $38.9 \%$ of the total variance (axis 1: $23.6 \%$ and axis $2: 15.3 \%$ ). The distribution of stations in the reduced multidimensional space along these two main axes varies between EUNIS habitats. Along axis 1, the location of the centroid of the stations of each habitat varies from the right (positive coordinates) with A5.14 (circalittoral coarse sediment) to A5.37 (deep circalittoral mud) with negative coordinates. On the second axis, meanwhile, there is a larger separation between habitats from A5.25 (circalittoral fine sand) with the most positive coordinates to $\mathrm{A} 5.37$ with the most negative values.

The alignment of EUNIS habitats along the first axis shows an association with sediment granulometry, with habitats comprising coarser sediments (i.e., A5.14 and A5.15; circalittoral coarse sediment and deep circalittoral coarse sediment respectively) on the right and those habitats 
comprising finer sediments (e.g. A5.37; deep circalittoral mud) towards the left. Similarly, the location of the stations of the various EUNIS habitats along the second axis follows a depth gradient, with stations belonging to shallower habitats e.g., A5.25: circalittoral fine sand, displaying positive coordinates and those belonging to the deeper A5.37 (deep circalittoral mud) displaying the most negative coordinates along this axis. Therefore, assemblage traits composition varies between habitats and the differences are best explained by gradients in sediment type and depth.

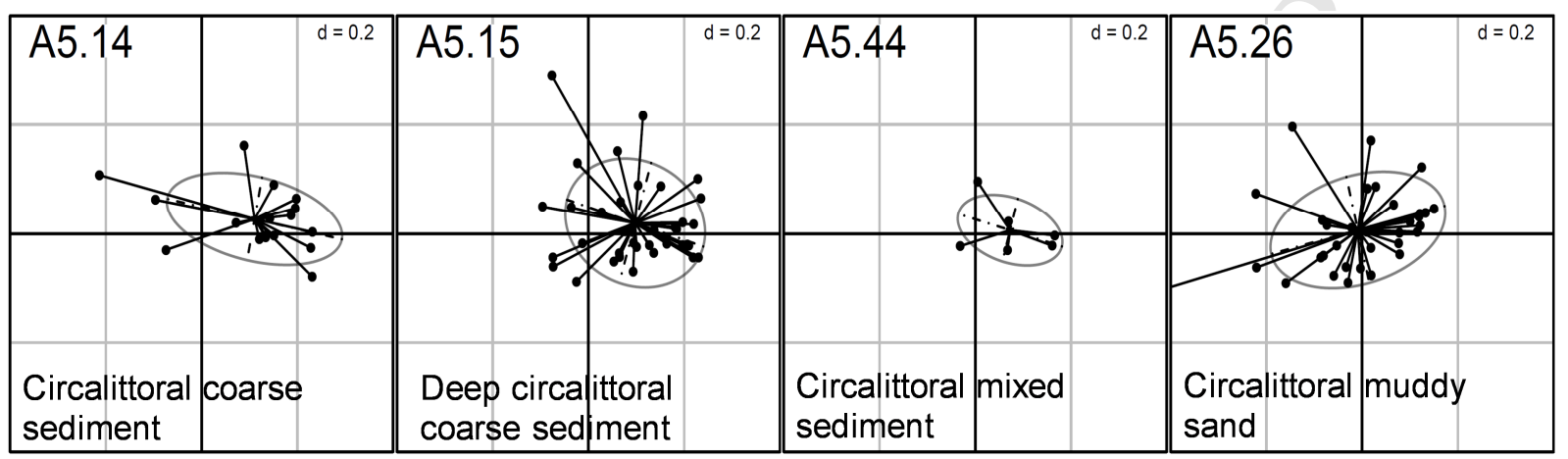

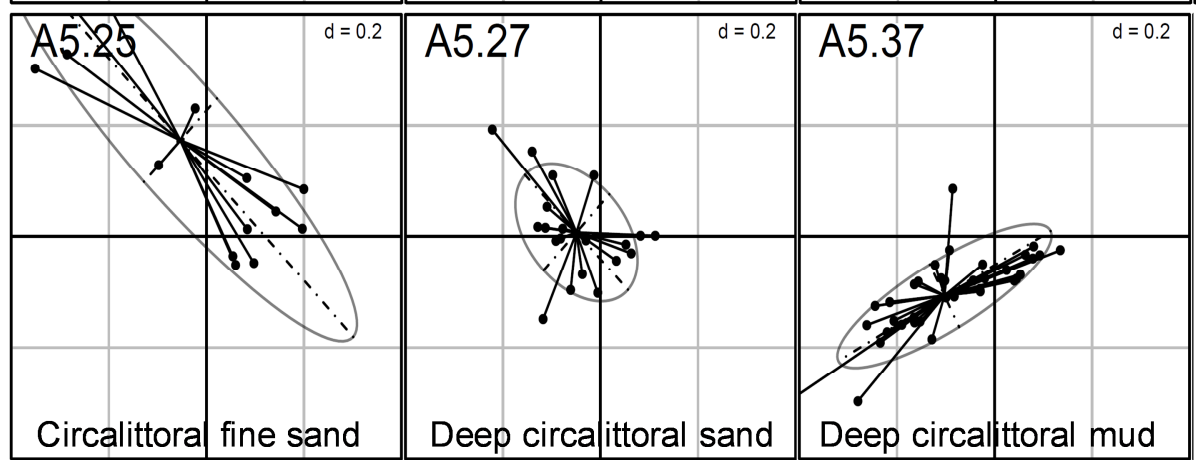

Figure 4. Biplot showing the relative similarities unfished stations for each EUNIS habitat based on their biological traits data ordinated along the two main axes of the Fuzzy Correspondence Analysis (FCA). The median location of the stations is given by the centroid (the origin of the vector lines) and the elipses represent the spread (95\%) of stations. Axes have been standardised between plots.

The relationships between the respective contributions of each environmental variable for each sample (i.e. gravel and mud content of the sediment and station depth) against the location of each sample on axes 1 and 2 in the FCA plot were found to be significant (axis 1: estimate $=9.3$, std. error $=3.0, z$ value $=3.1$ and $p$-value $=0.002$; axis 2 : estimate $=-18.8$, std. error $=4.8, z$ value $=-4.0$ and $p$ value $<0.001$ ). This confirms that there is a significant relationship between sediment granulometry and the location of the station along axis 1 and that of depth wih axis 2 of the FCA biplot (Figure 4). Only three stations with negative coordinates along the axis 1 in Figure 5, for example, possess sediments with $>10 \%$ gravel, and no station deeper than $80-100 m$ has positive coordinates along axis 2. 

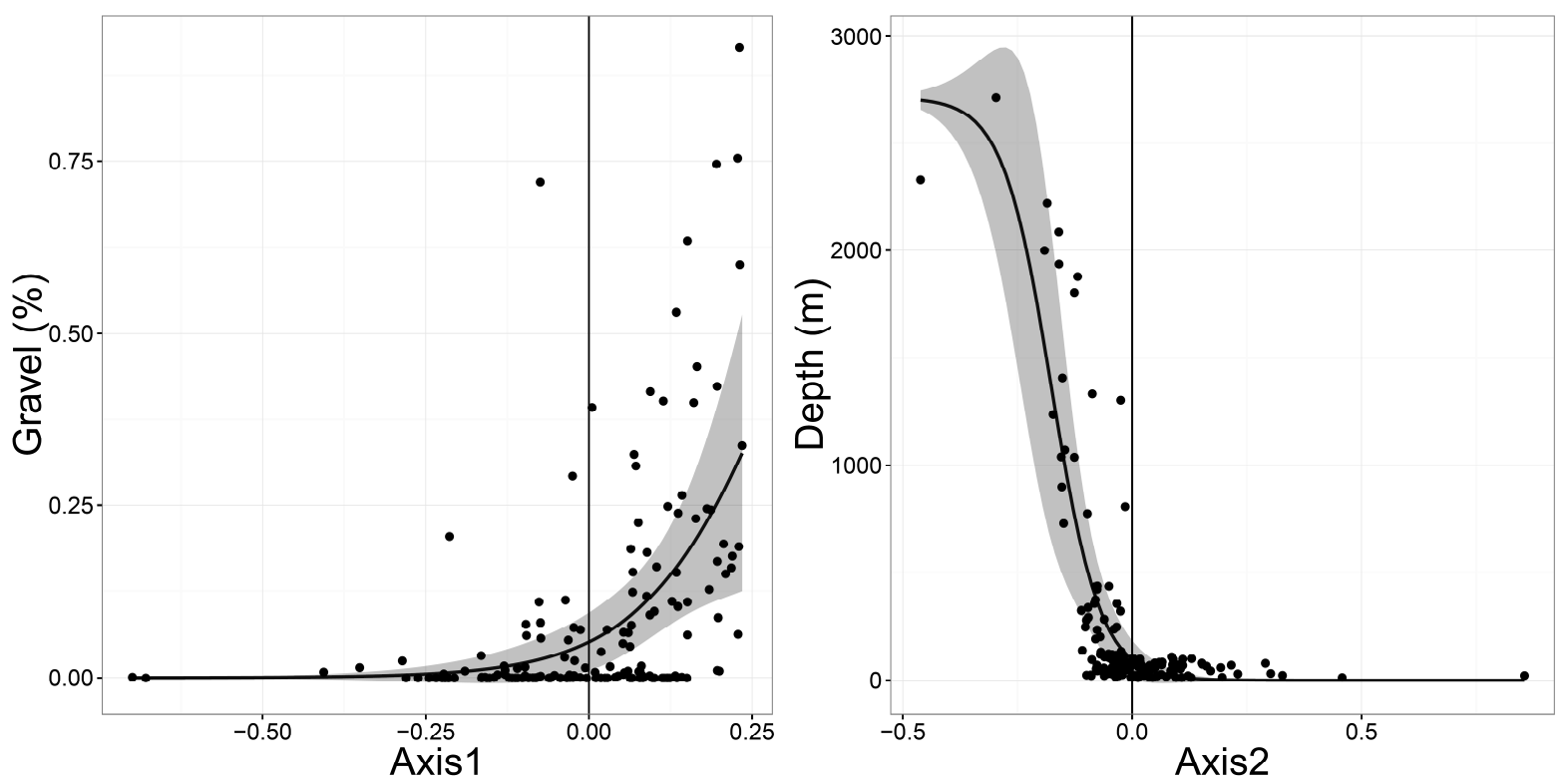

Figure 5. Relationships between gravel content (\%) (left) with axis 1 of the FCA biplot (Figure 4), and between depth $(\mathrm{m})$ (right) with axis 2 . The vertical solid lines show the origins for axes 1 and 2 . The fitted line and the shaded area represent a smoother and its $95 \%$ confidence interval calculated with a GLM binomial.

The FCA ordination of the 35 trait modalities as vectors (Figure 6) reveals that the traits vary with respect to their relative importance in determining the station differences observed on the FCA ordinations presented in Figure 4. A large number of trait modalities (e.g. bSurf, surface depositors; fSub, sub-surface deposit feeders; and sr10, species with a maximum size $<10 \mathrm{~mm}$ ) have relatively short vectors indicating they represent only a minor influence in determining differences in stations (Figure 6a). These trait modalities are, therefore, consistently found in either low proportions or high proportions within the assemblages of all the stations, regardless of habitat or environmental conditions. However, a notable number of trait modalities show significant variations in proportions between assemblages of unfished stations (Figure $6 \mathrm{~b}$ ). The two bioturbation modes bDiff (diffusive mixers) and bDownward (downward conveyors) for example, constitute significantly greater numerical proportions within the assemblages aligned towards the top and bottom of axis 2 respectively. Since this axis is most strongly correlated with depth, it follows that in unimpacted assemblages bDiff represents significantly higher numerical proportions in shallow regions while bDownward assumes a greater numerical representation in assemblages in deeper areas (Figure 7a). Similarly, trait modalities such as bNone (non-bioturbators), edAsex (asexual development) and sr500 (maximum size $>500 \mathrm{~mm}$, the largest size class) are displayed in greater numerical proportions of the assemblages with more positive coordinates along axis 1, or those typical of coarser sediment. Meanwhile, other traits such as edSex_pel (pelagic egg-producers) and sr21-100mm (organisms 
between $21-100 \mathrm{~mm}$ ) are favoured in muddier habitats (Figure $7 \mathrm{~b}$ ). While these significant trait modalities drive station differences in either of the two axes, five trait modalities (displayed in red in Figure $6 b)$ significantly drive station differences in both axes.
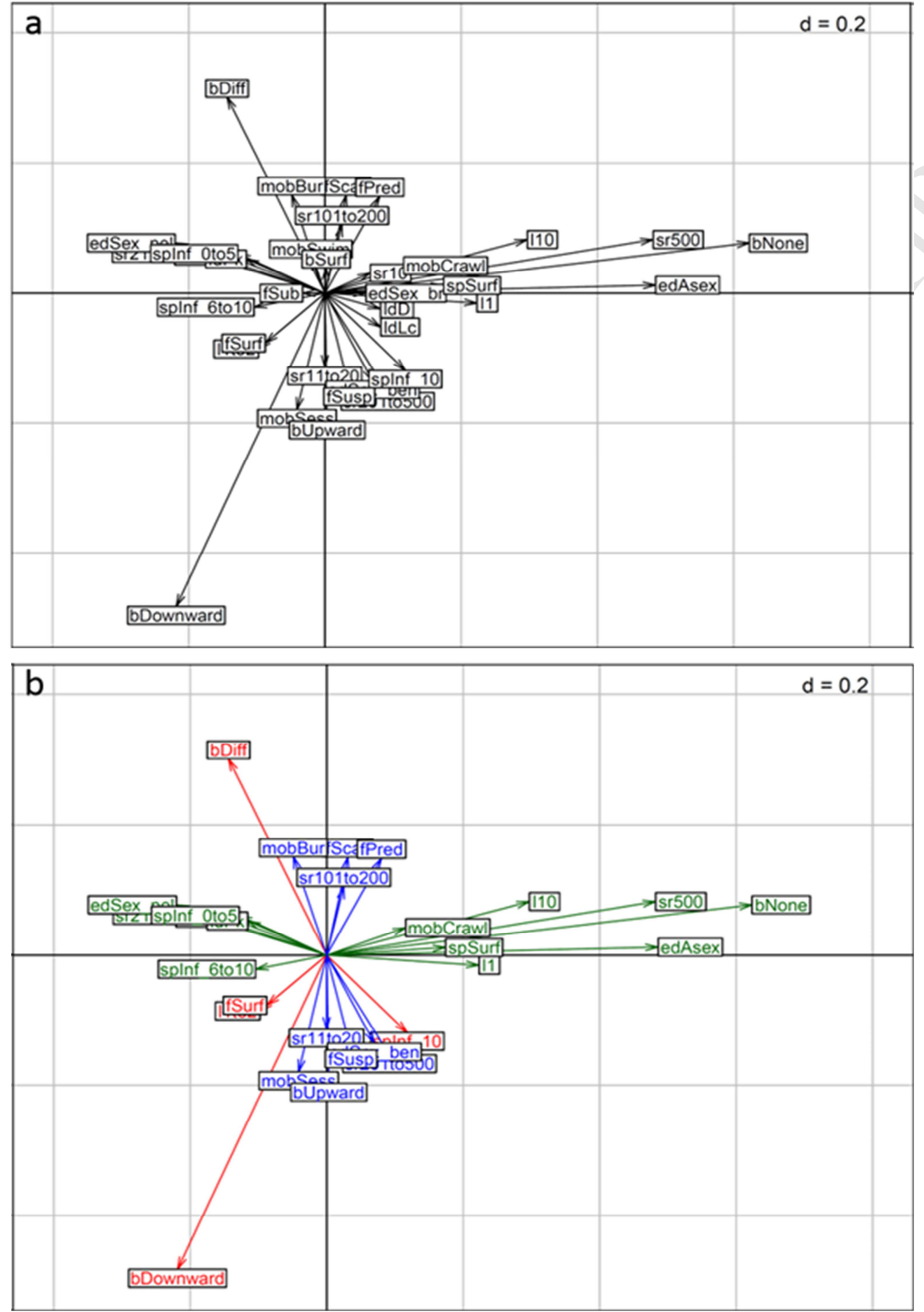

Figure $6(a, b)$. a) Ordination of the all trait modalities along the two main axes of the Fuzzy Correspondence Analysis (FCA) biplot for all stations (see Figure 4); b) the same ordination but displaying only significant modalities established by permutation analysis. Green indicates 
trait modalities which significantly contribute to both axes. For descriptions of trait modality codes see Table 2.

\section{(a) Axis 2}

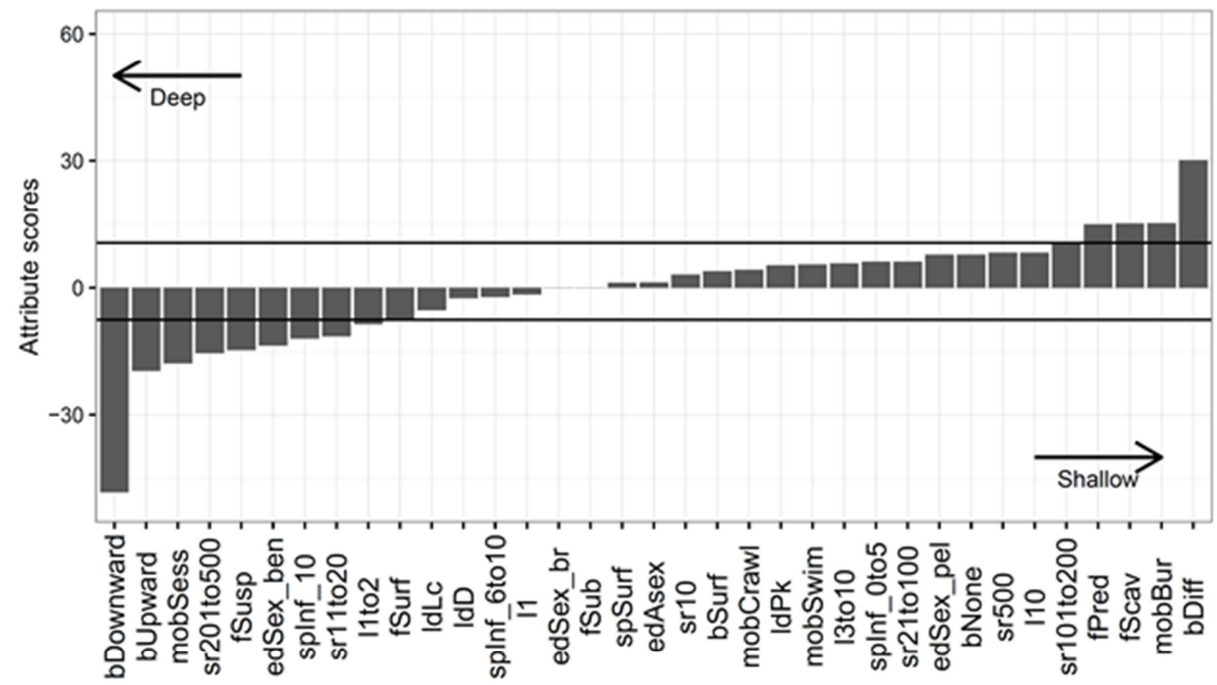

(b) Axis 1

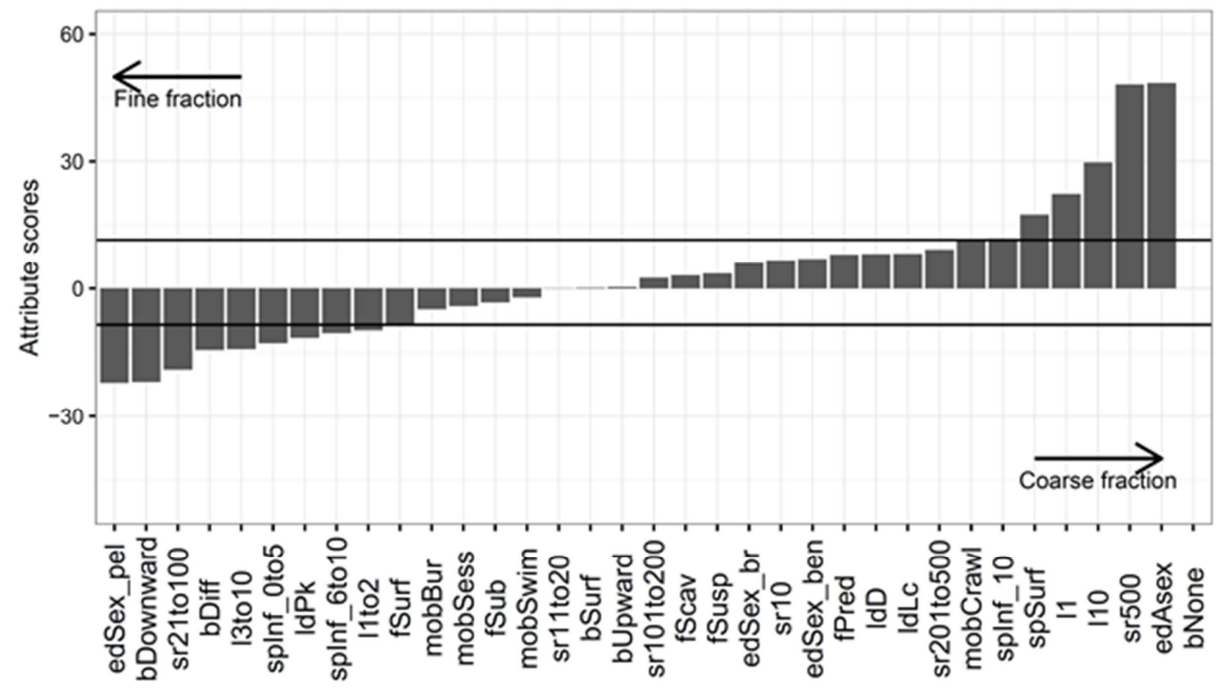

Figure $7(a, b)$. Scores of the trait modalities along (a) axis 2 depth, and (b) axis 1 sediment grain size, of the FCA showing their respective contributions to the two patterns identified. The solid line represents the significance established by permutation testing. For a description of trait modality codes see Table 2. 


\section{DISCUSSION}

This study aimed to determine the trait structure of soft-bottom invertebrate assemblages, to study their spatial variation and to investigate the factors that may be responsible for these variations. As the data used describe trait composition relate to a number of habitats which together comprise the majority of European shelf sedimentary regions, our results provide valuable information that could be used to plan more effective management policies for the protection of European shelf seas.

The scale of ecological processes affecting organisms has important implications for their population and community dynamics. Information on life history strategies of organisms, their colonisation potential and local adaptation and tolerance to environmental characteristics is important for interpreting spatial distribution patterns. The investigation of functional patterns of benthic invertebrate communities is not novel (Dimitriadis et al., 2012; Van Son et al., 2013); what is innovative in the present study is the expanded application of the concept in the interpretation of a field survey involving benthic sampling over a range of benthic habitats. Furthermore, previous large-scale studies aiming to determine the relationships between benthic traits with environmental conditions have rarely accounted for variability in fishing pressure. It is possible that correlations observed hitherto may, in part, reflect habitat-specific fishing effects (Webb et al., 2009). The major impacts that fishing has on the structure and traits composition of benthic assemblages (Thrush et al., 1995; Tillin et al., 2006; van Denderen et al., 2015) undoubtedly serves to support this notion. Demersal fishing affects significant proportions of the seabed in shelf waters and has an overwhelming effect on the seabed in terms of area than any other anthropogenic impact (Halpern et al., 2008; Foden et al., 2011; Eigaard et al., 2016b). Although some fishing exclusion areas exist, unlike other man-induced pressures fishing is largely not constrained to licensed boundaries, making it difficult to control for fishing impacts within large-scale spatial assessments.

In the absence of control or reference, a critical first step of this study prior to any exploratory analysis was to establish which of the 812 stations were deemed to represent an acceptable representation of unfished situations. The novel approach adopted here based on assemblage traits composition, was independently undertaken for EUNIS habitat assemblage to reduce the effect of environmental variability in determining the effects of fishing on traits composition. The authors believe that this methodology, which maintains information regarding changes in the composition of eight traits by its reduction to a functional diversity index measure (Petchey and Gaston's FD index), offers a more suitable approach than one based on taxonomic metrics (e.g., change in number of species, diversity). Rijnsdorp et al. (2015), however, recently assessed fishing impacts on benthic 
assemblages based on changes in the composition of a single functional trait, i.e., longevity. Our approach allowed a more accurate determination of the traits composition for each EUNIS habitat by allowing the inclusion of data from assemblages which were estimated to have been subjected to, but not impacted by, fishing. For instance, the number stations for which traits data could be used increased from two (i.e., number of stations with FP $=0 y^{-1}$ ) to 17 for A5.14 (circalittoral coarse sediment) while that for A5.26 (circalittoral muddy sediment) increased from three to 33 (Table 5). Of course, the incorporation of a greater number of sampling stations estimated to experience no fishing pressure (i.e. $F P=0$ ), would arguably have been a better alternative approach, but traits data from such a large number of stations are rarely available. Nevertheless, the present study has shown that it is still possible to include data which would have been otherwise excluded. Moreover, the increased number of stations used was enabled by the adoption of a transparent method which precluded the need to make well-intended albeit arbitrary cut-off points between fished and unfished based on best judgement.

One evident outcome (Figure 4) is the variability in traits composition of the stations within each EUNIS habitat and the overlap of stations from different habitats on the FCA biplots. There are two potential explanations for this. Firstly, it is possible that the relationships between traits composition and environmental conditions are not strong, or, secondly, the within-habitat variability reflects the wide-range of values of each environmental metric (e.g., depth, silt content, gravel content) used to classify EUNIS classes. For example, the gravel content of 'coarse sediment' habitats may range from anywhere between $5 \%$ and $100 \%$, with silt and sands occupying varying proportions of the remainder (Long, 2006). Given the close link between benthic assemblages and sediment granulometry (Snelgrove and Butman, 1994; Sanvicente-Anorve et al., 2002), this range is clearly likely to result in an array of assemblage types within each EUNIS habitat. In other words, allocating stations into discrete EUNIS classes possibly artefactually increases within-habitat variability, precluding the possibility of observing the true strength of the relationship between traits composition and environmental properties. This notion was supported by the significant relationships found between station location along the first two FCA axes with depth and sediment granulometric properties.

Overall, a large number of trait modalities included within the eight traits in this study was shown to display no significant relationship with EUNIS habitat or changes in depth or in sediment granulometry. These traits are either present in low (e.g., asexual reproducers, swimmers, smallbodied (<10mm long) individuals) or high numerical proportions (e.g., subsurface-deposit feeders, 
egg-brooders) in all macrofaunal assemblages regardless of the environmental setting. Meanwhile, the present study identified a number of trait modalities whose numerical proportions within an assemblage are shown to be correlated with changes in the environment. Unimpacted assemblages in deep, muddy environments show increased proportions of, for instance, downward conveyors and surface deposit-feeders, while traits such as burrowing, diffusive mixing, scavenging and predation assume greater numerical proportions in shallower habitats. Deep, coarser sediments tend to be dominated by sessile, upward conveyors and suspension feeders. In contrast, unimpacted assemblages of coarse sediments in shallower regions are proportionally dominated by the bioturbation mode diffusive mixers, as well as trait modalities burrowers, scavengers, predators and species with a maximum size of $200 \mathrm{~mm}$. Assemblages of gravelly sediments exhibit a relatively greater numerical dominance of non-bioturbators and asexual reproducers (Figure 6). Extrapolating the correlative relationships observed here to infer causal mechanisms must be made with great caution. Many physical properties covary, particularly those interacting with the seabed, e.g. sediment granulometry, bottom flow, bed shear stress. This makes it very difficult to disentangle the actual mechanisms responsible for the relationships between traits and the environment in the present study. Quantifying the importance of the various causal mechanisms ultimately requires targeted experimental approaches which, as yet, have not been conducted for the marine benthos. In this respect, intelligence is far behind that for terrestrial systems where the role of invertebrates in driving ecosystem processes in soils is better understood (Pey et al., 2014). Similarly, the recognised links between freshwater invertebrate traits and the environment has enabled relevant traits to be used as an important tool within biomonitoring approaches (Menezes et al., 2010).

An understanding of which traits, in principle, numerically dominate assemblages in anthropogenically-unimpacted habitats potentially allows a mechanism to assess the extent of trait compositional change of an observed assemblage. Such an approach has recently been conducted to assess the potential functional impacts of dredged material disposal on benthic traits composition (Bolam et al., 2016) which revealed that bioturbative functional traits such as surface deposition and diffusive mixers were favoured in impacted assemblages. However, unlike that for fishing, acquiring traits data to reflect the unimpacted scenario against which the impacted situation may be compared is relatively straightforward for dredged material disposal impacts. The approach adopted in the present study affords one method by which the issue can be addressed for the more widespread and less spatially-discrete pressure of fishing. For example, the present results reveal that unfished assemblages in deep environments possess increased numerical proportions of a number of trait modalities (e.g., sessile, suspension or filter-feeders; Figure 7) that have often been 
observed to be sensitive to fishing impacts (Tillin et al., 2006; de Juan et al., 2007; van Denderen et al., 2015). Our results, therefore, support the notion that infaunal assemblages in deep areas are likely to be relatively functionally-sensitive to fishing. Similarly, traits which assume greater numerical proportions in shallow areas such as scavengers, predators and burrowers (Figure 7), tend to be those relatively resistant to trawling (Tillin et al., 2006; van Denderen et al., 2015). Thus, shallow-water assemblages are likely to be relatively less sensitive to trawling-undiced functional impacts. The findings of the present study may, therefore, be used to form the basis of an approach to rank different habitats along a functional sensitivity trawling gradient; a central prerequisite to aid the sustainable management of this activity. Empirical data are now needed with respect to the relative sensitivity of benthic traits to other anthropogenic impacts, such as that for disposal (Bolam et al., 2016). This would similarly allow the present results to be used to rank the sensitivity of benthic habitats to a wider range of pressures.

Biological traits have previously been used to classify habitats into their relative sensitivity to fishing impacts. For example, Rijnsdorp et al. (2015) integrated high resolution VMS data to determine the frequency of seabed trawling, information on the distribution of seabed habitats and information on the traits of the benthic communities. They concluded that natural habitats which are composed of relatively short-lived taxa subjected to successive trawling impacts on a time interval less than the longevity of the longest-lived taxa were considered to be at low risk to fishing impacts. Such habitatspecific fishing effort limits, when applied to existing fisheries (VMS) data, could have utility in determining the risks of fishing impacts in areas which fall within overall fishing footprints. It may be tempting to use the present fishing pressure cut-off values derived here for the various habitats as an indicator of seabed resilience and/or resistance to assess seafloor integrity under the MSFD, as current approaches rely on expert judgement. However, adoption of our absolute cut-off values would currently be inadvisable. For example, the present study used limited data for a range of habitats whose sample frequency was not comparable across the various habitats. Furthermore, the method employed merely identified the first benthic sample along a fishing pressure gradient which deviated significantly in its traits composition. It is difficult to unequivocally quantify the relative effect of fishing compared to that resulting from natural variability for this significant deviation in trait composition, although the effect of the latter is minimised by undertaking the assessment for each habitat separately. Therefore, the applicability of the approach used here rests on further development using more data and with the limitations that pertain to this study overcome. The method could then potentially offer an alternative indicator of the relative sensitivity of seabed 
habitats to fishing impacts to further enhance our ability to set sustainable management measures across shelf seas.

\section{ACKNOWLEDGEMENTS}

The work undertaken herein was funded under WP3 of the EU FP7 Benthis project (312088). The article does not necessarily reflect the views of the European Commission and does not anticipate the Commission's future policy in this area. Much of the resource-exhaustive task of trait information collation for the infaunal taxa was supported by recent Cefas-led projects, one being the Defra-funded project ME5301. All the scientists involved in that laborious task are to be acknowledged here.

\section{REFERENCES}

Barrio-Froján, R.S., Bolam, S.G., Eggleton, J.D., Mason, C., 2012. Large-scale faunal characterisation of marine benthic sedimentary habitats around the UK. Journal of Sea Research 69, 53-65.

Bolam, S.G., Eggleton, J.D. 2014. Relationship between macrofaunal secondary production and biological traits: an investigation using data from UK shelf seas. Journal of Sea Research 88, 47-58.

Bolam, S.G., Eggleton, J., Smith, R., Mason, C., Vanstaen, K., Rees, H. 2008. Spatial distribution of macrofaunal assemblages along the English Channel. Journal of the Marine Biological Association of the UK 88(4), 675-687.

Bolam, S.G., Coggan, R.C., Eggleton, J.E., Diesing, M., Stephens, D. 2014. Sensitivity of macrobenthic secondary production to trawling in the English sector of the Greater North Sea: a biological traits approach. Journal of Sea Research 85, 162-177.

Bolam, S.G., Mcllwaine, P.O., Garcia, C. 2016. Application of biological traits to further our understanding of the impacts of dredged material disposal on marine benthic assemblages. Marine Pollution Bulletin 105, 180-192.

Bremner, J. 2008. Species traits and ecological functioning in marine conservation and management. Journal of Experimental Marine Biology and Ecology 366, 37-47. 
Buhl-Mortensen, L., Ellingsen, K. E., Buhl-Mortensen, P., Skaar, K. L., Gonzalez-Mirelis, G. 2015. Trawling disturbance on megabenthos and sediment in the Barents Sea: chronic effects on density, diversity, and composition. ICES Journal of Marine Science, doi: 10.1093/icesjms/fsv200.

Cabioch, L. 1968. Contribution à la connaissance des peuplements benthiques de la Manche occidentale. Cahiers de Biologie Marine 9, 493-720.

Cameron, A., Askew, N., 2011. EUSeaMap - preparatory action for development and assessment of a European broad-scale seabed habitat map. Final Report v2.8. EC contract no. MARE/2008/07, [http://jncc.gov.uk/euseamap].

CEC (Commission of the European Communities), 2008. Directive 2008/56/EC of the European Parliament and of the Council of 17 June 2008 Establishing a Framework for Community Action in the Field of Marine Environmental Policy (Marine Strategy Framework Directive), p. 22.

Chevenet, F., Doledec, S., Chessel, D., 1994. A fuzzy-coding approach for the analysis of long-term ecological data. Freshwater Biology 31, 295-309.

Collie, J.S., Hall, S.J., Kaiser, M.J., Poiner, I.R. 2000. A quantitative analysis of fishing impacts on shelfsea benthos. Journal of Animal Ecology 69, 785-798.

Crisp, D.J., 1984. Energy flow measurements. In: Holme, N.A., McIntyre, A.D. (Eds.), Methods for the Study of the Marine Benthos. Blackwell Scientific Publications, Oxford, pp. 284-372.

Davies, C. E., Moss, D., Hill, M.O. 2004. EUNIS Habitat Classification revised. Report to the European Topic Centre on Nature Protection and Biodiversity, European Environment Agency. October 2004. 310 pp. http://eunis.eea.europa.eu/upload/EUNIS_2004_report.pdf pp.

Diaz, S., Purvis, A., Cornelissen, J.H.C., Mace, G.M., Donoghue, M.J., Ewers, R.M., Jordano, P., Pearse, W.D., 2013. Functional traits, the phylogeny of function, and ecosystem service vulnerability. Ecology and Evolution 3(9), 2958-2975. 
Dimitriadis, C., Evagelopoulos, A., Koutsoubas, D. 2012. Functional diversity and redundancy of soft bottom communities in brackish waters areas: local vs regional effects. Journal of Experimental Marine Biology and Ecology 426-427, 53-59.

Eastwood, P.D., Mills, C.M., Aldridge, J.N., Houghton, C.A., Rogers, S.I. 2007. Human activities in UK offshore waters: an assessment of direct, physical pressure on the seabed. ICES Journal of Marine Science 64, 453-463.

Eigaard O.R., Bastardie, F., Hintzen, N.T., Buhl-Mortensen, L., Buhl-Mortensen, P., Catarino, R., Dinesen, G.E., et al. 2016a. The footprint of bottom trawling in European waters: distribution, intensity and seabed integrity. ICES Journal of Marine Science (in press).

Eigaard, O.R., Bastardie, F., Breen, M., Dinesen, G., Hintzen, N., Laffargue, P., Nielsen, J., et al. 2016b. Estimating seabed pressure from demersal trawls, seines, and dredges based on gear design and dimensions. ICES Journal of Marine Science, 73(Supplement 1): i27-i43. doi:10.1093/icesjms/fsv099

Elliott, M., Quintino, V., 2007. The estuarine quality paradox, environmental homeostasis and the difficulty of detecting anthropogenic stress in naturally stressed areas. Marine Pollution Bulletin 54, 640-645.

Foden, J., Rogers, S.I., Jones, A.P. 2011. Human pressures on UK seabed habitats: a cumulative impact assessment. Marine Ecology Progress Series 428, 33-47.

Galparsoro, I., Connor, D.W., Borja, A., Aish, A., Amorim, P., Bajjouk. T., Chambers, C., Coggan, R., Dirberg, G., Ellwood, H., Evans, D., Goodin, K.L., Grehan, A., Haldin, J., Howell, K., Jenkins, C., Michez, N., Mo, G., Buhl-Mortensen, P., Pearce, B., Populus, J., Salomidi, M., Sánchez, F., Serrano, A., Shumchenia, E., Tempera, F., Vasquez, M. 2012. Using EUNIS habitat classification for benthic mapping in European seas: present concerns and future needs. Marine Pollution Bulletin 64(12), 2630-2638.

Halpern, B.S., Walbridge, S., Selkoe, K.A., Kappel, C.V., Micheli, F., D’Agrosa, C., Bruno, J.F., et al. 2008. A global map of human impact on marine ecosystems. Science 319, 948-952. 
Hiddink, J.G., Jennings, S., Kaiser, M.J. 2007. Assessing and predicting the relative ecological impacts of disturbance on habitats with different sensitivities. Journal of Applied Ecology 44, 405-413.

Hiddink, J.G., Davies, T.W., Perkins, M., Machairopoulou, M., Neill, S.P. 2009. Context dependency of relationships between biodiversity and ecosystem functioning is different for multiple ecosystem functions. Oikos 118, 1892-1900.

Jennings, S., Kaiser, M.J. 1998. The effects of fishing on marine ecosystems. London, Academic Press. pp.203-314.

Kaiser, M.J., de Groot, S.J. 2000. The effects of fishing on non-target species and habitats. Oxford, Blackwell Science pp. 416.

Jennings, S., Blanchard, J.L., 2004. Fish abundance with no fishing: predictions based on macroecological theory 73, 632-642.

Kaiser, M.J., Collie, J.S., Hall, S.J., Jennings, S. and Poiner, I.R. 2002. Modification of marine habitats by trawling activities: prognosis and solutions. Fish and Fisheries 3(2), 114-136.

Kaiser, M.J., Ramsay, K., Richardson, C.A., Spence, F.E., Brand, A.R. 2000. Chronic fishing disturbance has changed shelf sea benthic community structure. Journal of Animal Ecology 69, 494-503.

Linting, M., van Os, B.J., Meulman, J.J. 2011. Statistical significance of the contribution of variables to the PCA solution: an alternative permutation strategy. Psychometrika 76, 440-460.

Long, D. 2006. BGS detailed explanation of seabed sediment modified folk classification. http://www.emodnet-seabedhabitats.eu

Marchini, A., Munari, C., Mistri, M. 2008. Functions and ecological status of eight Italian lagoons examined using biological traits analysis (BTA). Marine Pollution Bulletin 56, 1076-1085.

Menezes, S., Baird, D.J., Soares, A.M.V.M. 2010. Beyond taxonomy: a review of macroinvertebrate trait-based community descriptors as tools for freshwater biomonitoring. Journal of Applied Ecology 47, 711-719. 
Petchey, O.L., Gaston, K.J., 2002. Functional diversity (FD), species richness and community composition. Ecology Letters 5(3), 402-411.

Pey, B., Nahmani, J., Auclerc, A., Capowiez, Y., Cluzeau, D., Cortet, J., Decaens, T., Deharveng, L.,

Dubs, F., Joimel, S., Briard, C., Grumiaux, F., Laporte, M.A., Pasquet, A., Pelosi, C., Pernin, C., Ponge, J.F., Salmon, S., Santorufo, L., Hedde, M. 2014. Current use of and future needs for soil invertebrate functional traits in community ecology. Basic and Applied Ecology 15(3), 194-206.

Rice, J.C. 2003. Environmental health indicators. Ocean and Coastal Management 46, 235-259.

Rijnsdorp, A.D., Bastardie, F., Bolam, S.G., Buhl-Mortensen L., Eigaard O.R., Hamon K., Hiddink J.G., Hintzen N.T., Ivanovic A., Kenny A., Laffargue P., Nielsen R.N., O’Neill F.G., Piet G.J., Polet H., Sala A., Smith C., van Kooten T., Zengin M., (2015). Towards a framework for the quantitative assessment of trawling impacts on the sea bed and benthic ecosystems. ICES Journal of Marine Science 73(1), 2738.

Sanvicente-Añorve, L., Lepêrtre, A., Davoult, D., 2002. Diversity of benthic macrofauna in the eastern English Channel: comparison among and within communities. Biodiversity and Conservation 11: $265-282$.

Snelgrove, P.V. 1997. The importance of marine sediment biodiversity in ecosystem processes. Ambio 26, 578-583.

Snelgrove, P.V., Butman, C.A., 1994. Animal-sediment relationships revisited: cause versus effect. Oceanography and Marine Biology: an Annual Review 32, 111-177.

Tagliapietra, D., Pavan, M., Wagner, C. 1999. Macrobenthic community changes related to eutrophication in Pallude della Rosa (Venetian lagoon, Italy). Estuarine, Coastal and Shelf Science 47, 217-226.

Thioulouse, J., Chessel, D., Doledec, S., Olivier, J.M. 1997. ADE-4: a multivariate analysis and graphical display software. Statistical Computing 7, 75-83. 
Thrush, S.F., Hewitt, J., Cummings, V., Dayton, P. 1995. The impact of habitat disturbance by scallop dredging on marine benthic communities: what can be predicted from the results of experiments? Marine Ecology Progress Series 129, 141-150.

Thrush, S. F., Ellingsen, K. E., Davis, K. 2014. Implications of fisheries impacts to seabed biodiversity and ecosystem-based management. ICES Journal of Marine Science, doi: 10.1093/icesjms/fsv114.

Tillin, H.M., Hiddink, J.G., Jennings, S., Kaiser, M.J. 2006. Chronic bottom trawling alters the functional composition of benthic invertebrate communities on a sea-basin scale. Marine Ecology Progress Series 318, 31-45.

Usseglio-Polatera, P., Bournaud, M., Richoux, P., Tachet, H. 2000. Biomonitoring through biological traits of benthic macroinvertebrates: how to use species trait databases? Hydrobiologia 422/423, 153-162.

Van Denderen, P.D., Bolam, S.G., Hiddink, J.G., Jennings, S., Kenny, A., Rijnsdorp, A.D., van Kooten, T. 2016. Interactive effects of bottom trawling and natural disturbance on benthic invertebrate community composition in soft-sediment habitats. Marine Ecology Progress Series 541, 31-43.

Van Hoey, G., Borja, A., Birchenough, S., Buhl-Mortensen, L., Degraer, S. et al., 2010. The use of benthic indicators in Europe: from the Water Framework Directive to the Marine Strategy Framework Directive. Marine Pollution Bulletin 60 (12), 2187-2196.

Van Son, T.C., Oug, E., Halvorsen, R., Melsom, F. 2013. Gradients in traits composition and their relation to environmental complex-gradients and structuring processes: a study of marine sediment species communities. Open Marine Biology Journal 7, 14-27.

Violle, C., Navas, M.-L., Vile, D., Kazakou, E., Fortunel, C., Hummel, I., Garnier, E., 2007. Let the concept of trait be functional! Oikos $116,882-892$.

Webb, T.J., Tyler, E.H.M., Somerfield, P.J. 2009. Life history mediates large-scale population ecology in marine benthic taxa. Marine Ecology Progress Series 396, 293-306. 
- A trait-based approach is used to determine how functional characteristics of unimpacted benthic assemblages vary between different sedimentary habitats.

- Assemblages in deep, muddy environments unaffected by anthropogenic disturbance show increased proportions of downward conveyors and surface deposit-feeders.

- Burrowing, diffusive mixing, scavenging and predation traits assume greater numerical proportions in shallower habitats.

- Deep, coarser sediments are numerically more dominated by sessile, upward conveyors and suspension feeders.

- Coarse sediments in shallower regions are proportionally dominated by the diffusive mixers, burrowers, scavengers and predators.

- These findings may be used to form the basis of ranking habitats along a functional sensitivity gradient. 